\title{
Study on Aerobics Teaching Reform and Fashionable Fitness Dance
}

\author{
Ning Kang \\ Liaoning Jidian Polytechnic, Dandong, 118000, China
}

\begin{abstract}
Keywords: Fashionable aerobics, Physical education, College physical education
\end{abstract}
\begin{abstract}
Physical education is an indispensible teaching content in colleges teaching and plays a very important function in improving students' physical quality and psychological health. Aerobics teaching is a very significant course in physical education. It can not just enhance students' physical quality and enrich after-class life, but also shape body. It is deeply welcomed by vast college students. This paper mainly deeply studies aerobics teaching reform in colleges and fashionable fitness dance and indicates the important position of aerobics teaching and fashionable fitness dance in college physical education.
\end{abstract}

\section{Introduction}

Fashion has been a theme college students pursue and is also reflected in college physical education. Fashionable aerobics as a kind of fashionable physical education widely exists in college physical education. As early as 2003, Physical Education Bureau has held "fashionable exercise and fitness seminar" in many cities and defines fashion as a fitness item integrating fitness, training, entertainment and relaxation. Fashionable fitness dance can combine traditional physical education form with modern dance, such as hip-hop, Latin dance and yoga. Besides, such fitness sport is also an athletics item, is deeply studied in terms of the teaching method and deeply welcomed by college students.

\section{Overview of fashionable fitness dance}

\section{Definition of fashionable fitness dance}

Fashionable fitness dance is actually a kind of fitness mode fusing sport, dance and various art expression forms. In recent years, as fashionable fitness dance becomes popular in colleges, the contents it covers gradually increase. In continuous development process, the following dance types are derived: hip-hop, Latin dance, jazziness, yoga and aerobic boxing etc. These fitness dances can fully fuse sport and music. The expression forms become more cheerful. Dance performers can relax their mind and body while performing dance. If learners have the talent for performing fitness dance, they may participate in some competitions. Each college will regularly holds various fashionable fitness dance competitions annually to enrich students' after-class life, cultivate their sentiment and increase their art expression ability. It thus can be seen that fashionable fitness dance is a fitness item with ornamental value, competition nature and performance nature.

\section{Features of fashionable fitness dance}

Fashionable fitness dance is visually compared to "relaxing sport" by many people by virtue of its healthy and joyful expression form, and reflects China's quality-oriented education. Some experts point out that, fitness dance can enhance human physique. If people stick to exercise for a long time, disease incident rate can decrease and people can extend life. The expression form of fashionable fitness dance is very relaxing, cheerful and free. Exercise intensity is proper. Thus, it is welcomed by many college students. A survey shows the proportion of college students conducting fitness dance regularly is large in total sport activities. Besides, disease incident rate of those sticking to participating in fashionable fitness dance is below 30\% and their longevity will extend for 3-4 years. Specific characteristics of fashionable fitness dance are shown in the following aspects:

Free from time and exercise intensity limit 
It is known from the above content that fissionable fitness dance is relaxing and active in terms of expression form. Thus, fissionable fitness dance has no special rules and limits in terms of expression time. People may utilize spare time to exercise or spare some time for training in the morning or evening. The exercise time can be decided according to individual actual physical conditions. If one has sufficient energy in the morning, he may exercise for more time. If one's time or physical strength has not reached the best state, exercise time may shorten. Moreover, in the process of practicing fitness dance, physical strength consumption is small (generally 1700 2000). This is very beneficial to human health.

Small economic input and no excessive economic burden

One does not need high talent to practice fashionable fitness dance. It has no too many technological requirements. As long as one participates in the dance, he can feel the atmosphere. Even those without any dance foundation can also exercise it. Those exercise fitness dance should own positive mentality. Additionally, many sport forms need professional devices, so exercisers need to input many funds and much energy. For example, some sports are conducted in gymnasium or swimming pool. If one employs a coach, he will input more money and time and exercise according to the time and standard specified by the coach. Exercisers cannot exercise according to the coach's time arrangement sometimes due to work or study, and thus waste funds. Besides, they do not experience many benefits. In particular, it is hard for many students to persist in view of academic pressure. But, one can practice fitness dance anytime and anywhere to really achieve the purpose of strong economical efficiency and high training value.

\section{College aerobics teaching reform}

\section{Main teaching content of college aerobics}

Various surveys show that in aerobics teaching, many college students cannot keep pace with dance steps, postures and music rhythm and have some misunderstanding of aerobics. Their body coordination is not strong. Hence, aerobics teaching attaches great importance to learning dance steps and postures and laying a foundation for future study. Important contents of aerobics in classroom include the following:

1). Basic movement. In many movements of college aerobics, there are many arm and space movements, and these are important movements. It thus can be seen that it is very important to learn basic movements. In classroom, those who do not receive professional training or contact aerobics the first time may firstly practice basic movements, such as basic standing posture, basic steps and basic hand movement. Aerobics can improve students' body coordination and lay a good foundation for future study.

2). Shape training. The beauty of aerobics in performing process is very significant. So, it is required to shape students' shape, and the key point lies in basic posture. For instance, many students have many postures influencing beauty such as lowering their head. Teachers should correct these defects in teaching. Shaping good shape cannot be completed in one or two days. Students must practice and train in each class, which has an important function for correcting students' bad shapes in time.

3). Movement force of aerobics. Aerobics movement is the soul. The teaching purpose of aerobics is to enhance students' physique. Hence, certain movement force is needed as movement foundation. If the movement lacks force, aerobics will lose whole sense of beauty, and the function of body building cannot be achieved. Thus, teachers should continuously guide students to do each movement powerfully in teaching.

4). Music. The purpose of music is to cooperate with aerobics movement, make aerobics better own rhythm sensation and happy feeling and make dance steps have better atmosphere and feeling. Meanwhile, music is also a kind of exhilarant enhancing students' learning initiative. So, to enhance students' comprehensive ability of music and cognitive power and reinforce students' music rhythm sensation, teachers may first play music before teaching students aerobics, make students blend in dance study faster, and teach them to count the bats and seek the rhythm between music and dance. 


\section{Problems and strategies of college aerobics teaching}

\section{Problems of college aerobics teaching}

College aerobics teaching is traditional physical education which developed early. Such physical education expression form lays emphasis on students' physiological and psychological needs and changes, but pays no attention to students' individual needs. Furthermore, restricted by college teaching facilities pr teaching idea, many colleges cannot effectively carry out aerobics teaching. The detailed problems are as follows:

1). Teaching content is too single

College aerobics teaching has certain differences with bodybuilding exercise in some gymnasiums, because colleges bring aerobics in physical education category. There are specific provisions for the expression form, time and place. Nowadays, aerobics teaching in many colleges are carried out in accordance with teaching program. Many movements are traditional and stereotyped, and cannot adapt popular movement. Thus, teaching content is very single, and teaching time is fixed. This will certainly influence students' learning interest. Since the teaching materials cannot keep pace with the era, college aerobics development will encounter bottlenecks. College aerobics will gain more healthy and continuous development only through reform.

2). Aerobics teaching method is simple and there is short of flexibility

Based on the above, the expression form of fashionable fitness dance is very active and flexible. There are many consistent points between college aerobics and fashionable fitness dance. Hence, aerobics can be expressed in a flexible form. But, aerobics teaching in many colleges still adopt traditional physical education. Teaching is still dominated by teachers' explanation and demonstration. Teachers will first explain basic movements and then demonstrate some movements. Then, students are required to exercise by themselves. As well, many movements are copied from contents on the teaching materials and lack sense of beauty and era atmosphere. Such crammed teaching means ignores students’ personalized development. Quite a few students feel the classroom is dull and cannot fully show features of aerobics. In addition, the exchanges between students and teachers are very few. They cannot keep pace with some dance steps so that their self-confidence suffers serious setbacks.

3). Aerobics movement and background music are simple

Aerobics arrangement will be in strict accordance with dance steps in teaching materials, and the sequence cannot be disordered. There are many repeated movements. In terms of background music of movements, single music will be adopted based on movement needs. Students cannot carry out flexible movements as needed by themselves, and the melody is short of distinct features. Students' learning enthusiasm is low.

Development countermeasures of college aerobics teaching

Teaching method is very crucial. Effective teaching means can alter low impression and sense of repression due to influence of traditional teaching so that classroom teaching atmosphere is more cheerful and active. The teaching strategies which may be applied include the following:

1). Situational teaching method. Situational teaching method is a very effective teaching method in college aerobics teaching. The specific situations set up can render atmosphere and mobilize students' learning initiative. So, in college aerobics study, it is very significant to create favorable learning and practice atmosphere. This is because many students take part in aerobics study the first time and have certain burden mentally. As a result, their movements are stiff and their enthusiasm is low. Other students will reduce learning and practice. Teachers should accurately show important movements in teaching process and boldly do various movements. Plus passionate music, students will naturally blend in the aerobics and boldly practice various movements.

2). Interactive teaching. Interactive teaching means students or students and teachers adopt interactive experience-based teaching. Such teaching method can achieve communication between the teacher and students and make students better grasp learning skills and avoid unnecessary detours. In many gymnasiums, exercisers will follow the coach to practice, and such exercise is continuous and ceaseless. Exercisers even generate dependence. The cause of generating such good training effects is that the coach can apply language or body to interact with exercisers and mobilize training 
atmosphere. Teachers organize students to warm up before training and shout out boldly the slogan full of rhythm sensation. In this way, students will be more excited and improve their enthusiasm.

3). Group teaching method. Group teaching method means students are classified into several groups, and each group includes one students with standard movements. Such student can serve as the example in the group and provide demonstration for other members. In this way, students can learn the key skills faster. Moreover, group competitions may be organized. In teaching, many students and especially those with low learning interest cannot keep enthusiasm and initiative. This gives rise to negative guiding function. So, group competitions can concentrate students' attention and make students maintain full attention anytime.

\section{Conclusion}

In one word, some shortcomings appear inevitably in college aerobics teaching. These are decided by students themselves and educators' cognition or teaching ability. To make aerobics march toward a new level, it is required to explore appropriate teaching means and really give play to the value of aerobics.

\section{References}

[1] Hong Tao, Zhang Ying, Experimental study on cultivating students' physical education innovation ability with "innovative" teaching of college aerobics teaching. Journal of Beijing University of Physical Education, 2010, 29(4):536-538.

[2] Zhao Ying, Social value positioning of college aerobics teaching under perspective of nationwide fitness campaign. Journal of Lanzhou Institute of Education, 2014(12):101-102

[3] Song Cuicui, Sun Qin, Experimental study on introducing “creative competition” in college aerobics teaching assessment. Journal of Beijing University of Physical Education, 2011,31(1):105-107

[4] Yu Xiaodi, Causes for low practical value of college aerobics teaching and correction approaches. Journal of Chifeng University (Natural Science), 2014(22):71-72

[5] Wang Mei, Application of “dominance-subject” teaching mode in college aerobics teaching. Journal of Chifeng University (Natural Science), 2013(19):132-133 